\title{
The Impact of Serious Game on the Nursing Students' Learning, Behavioral Engagement and Motivation
}

\author{
https://doi.org/10.3991/ijet.v17i01.26857 \\ Wissam EL Machtani EL Idrissi ${ }^{1,2(\llbracket)}{ }^{\circledR}$, Ghizlane Chemsi ${ }^{1}$, Khadija EL Kababi ${ }^{3}$, \\ Mohamed Radid ${ }^{1,4}$ \\ ${ }^{1}$ Hassan II University of Casablanca, Casablanca, Morocco \\ ${ }^{2}$ Higher Institute of Nursing and Health Techniques of Casablanca, Casablanca, Morocco \\ ${ }^{3}$ Regional Centre for Education and Training Professions, Casablanca-Settat, Morocco \\ ${ }^{4}$ Observatory of Research in Interdisciplinary Didactics and University Pedagogy, Morocco \\ Wissam.elmachtanil-etu@etu.univh2c.ma
}

\begin{abstract}
Digital game-based learning is a ludic approach that has evolved through the development of information and communication technologies (ICT), making the learner an active participant in the virtual learning environment instead of a mere observer. It is an electronic simulation tool suitable for improving learning efficiency as well as learner engagement and motivation. The integration of this educational technology in the teaching and learning process can contribute to the construction of knowledge, the development of new skills and attitudes among students. The purpose of this study is to investigate the impact of serious game on the learning, behavioral engagement, and motivation of nursing students. To do this, we first conducted a study with a sample of 58 polyvalent nursing students divided into two groups; one experimental and the other as a control. Both groups benefited from the same content taught at a distance, however, the experimental group benefited from an online serious game after the course. By comparing the summative scores of the two groups using the Student's t-test, the results show that the serious game improved the students' clinical knowledge of pediatric nursing $(t=-2.706, p=0.009)$. However, it did not have an effect on clinical skills $(t=-0.373, p=0.711)$. As a second step, we have studied the impact of the game on the learners' behavioral engagement based on the analysis of the digital traces of the students' work. Meanwhile, the motivation is analyzed using a questionnaire developed from the ARCS scale of Killer (2010), which is distributed to the experimental group. By comparing the means and deviation standards, the results show that the students give the satisfaction factor the highest score $(4.71 \pm 0.34)$ followed by the relevance, attention, and confidence factors. To obtain reliable results, however, it is necessary to repeat the serious game experience in several nursing modules. In addition, the impact of combining serious game with simulation on the learning of nursing students should be studied.
\end{abstract}

Keywords-serious game, nursing students, clinical learning, motivation, engagement 


\section{Introduction}

Digital technology improves the understanding of the theoretical contents taught and facilitates the articulation between theory and practice. At the same time, it decreases anxiety among students [1]-[4]. In this context, digital game-based learning is a ludic approach that has emerged with the development of information and communication technologies (ICT) making the learner an active participant in the virtual learning environment instead of a mere observer [5]. Therefore, the integration of this educational technology in the teaching and learning process can contribute not only to the construction of knowledge and the development of new skills and attitudes in the student but also help teachers in their practice[5]-[7].

In the field of health, nursing students encounter difficulties in transferring clinical knowledge into skills and competencies, and also in adapting to the real clinical environment; difficulties related to critical thinking and reflection skills necessary for a nursing diagnosis [8], [9]. Therefore, the integration of serious games allows for an improvement in learning efficiency, a strong involvement and commitment of the learner in situations allowing for the transfer of knowledge, as well as a preparation for real-life situations in a safe setting [6], [8], [9].

Moreover, several authors have described the advantages and benefits of integrating the serious game into student learning, namely; the possibility of sharing the game with an unlimited number of students, the flexibility of access in time and space, and the unlimited number of repetitions. In addition, the student can progress at his or her own pace, and the teacher can monitor and evaluate the student's progress and actions [10], [11]. The serious game, through the challenges and learning opportunities it offers, allows the learner to build self-confidence, autonomy and decision-making capacity before taking charge of real patients [12], [13].

Moreover, studies demonstrate that learners are more motivated to engage in learning activities that use information and communication technologies (ICT) than in traditional classroom practices [14]. In particular, serious game and simulation contribute to changing their attitudes towards learning [15].

Nevertheless, the integration of the serious game allows the student to demonstrate clinical learning in a safe simulated setting [16]-[19] and at the same time makes it easier for the teacher to monitor the students' progress and measure the levels of learning achieved through appropriate feedback [16], [20], [21].

Therefore, the serious game can be a complementary tool to other learning methods adopted, given its cost, easy use and acceptance by students.

Nonetheless, and according to Kiili (2005), a serious game environment must meet the following fundamental criteria: clear objectives based on prior learning, the history of the setting, the presence of challenges and a grading system, feedback, as well as the aspect of playability and the student's sense of control [22]-[24]. These welldesigned criteria allow reinforcing the external motivation of the student through these 4 facets which are; attention, relevance, confidence, and satisfaction [25].

Although training in Morocco's higher institutes of nursing and technical health professions (ISPITS) has been reformed through the adoption of the LMD system and the competency-based approach, teachers continue to encounter difficulties in inte- 
grating ICTs and in assessing students' clinical learning [26]. A study conducted in several ISPITS with a total of seven showed that their training on assessment is mostly focused on theoretical concepts of assessment and the design of assessment tools $(75.2 \%)$, at the expense of the use of innovative tools such as simulation $(13.8 \%)$. This is due to the lack of resources and simulation laboratories [27].

The problem question we want to address is part of a strategy to improve learning and motivation among nursing students. It aims to study the impact of serious game on the learning of nursing care in pediatrics among nursing students and on their engagement and motivation.

As such, our problematic aims to answer two questions:

1. To what extent does serious game contribute to improving nursing learning among polyvalent nursing students?

2. What is the impact of serious game on behavioral engagement and motivation of polyvalent nursing students?

\section{$2 \quad$ Literature review}

\subsection{Digital game based learning}

Digital game-based learning is an approach that is based on three fundamental factors; structure, participation, and appearance of the game. The first factor is structure, which allows for better integration of the student into the game and builds confidence through a clear demonstration of the game's rules, objectives, and overall activities. Unlike simulation, the second factor acts on attention and relevance by motivating the player through challenges, the integrated scoring system, and the game levels in a fun atmosphere. The last factor in turn reinforces the learner's attention through the presence of audio, graphics, and animated elements with multimedia effects [13], [28], [29].

Moreover, virtual simulation is a resource in nursing education, which has an impact on the achievement of educational objectives of training [9], [30] . Indeed, students prefer the study of cases in a virtual simulation environment offering opportunities for practical experimentation because they reinforce the traditional cases and facilitate the management of real patients [7].

\subsection{Serious game}

In education, a serious game presents a learner-centered approach that uses virtual simulation to mimic reality. It is a complementary tool to optimize the acquisition of clinical skills, to complement simulation and to stimulate student motivation [5], [12], [31].

Serious games have fundamental characteristics; the use of a synthetic rule structured world, feedback mechanisms, and challenges to guide learners in knowledge development and its transfer [13], [16], [31]. 
Paper - The Impact of Serious Game on the Nursing Students' Learning, Behavioral Engagement and ...

Several advantages have been attributed to serious game; development of knowledge, skills, autonomy, motivation, decision making in the student, and also the ability for the teacher to evaluate and monitor the student's progress [13], [32].

\subsection{Serious game and evaluation}

The serious game can be a formative evaluation tool, complementary to the learning evaluation tools adopted, given that evaluation is a fundamental component of the game, through scores, levels, ranking [16], and feedback [33], [34].

This evaluation provides information on the behavior and performance of the player through the correct answers, the objectives reached and the steps taken [35].

Moreover, the evaluation can take several forms. (1) Internal to the game by studying the score and the objectives reached, the resources mobilized, and the difficulties encountered in achieving a specific objective. (2) Outside the game, either before, during, or after the game by using interviews, MCQ,s or development questions. (3) Within the game, as an integral part that does not interrupt the game experience and the study of the student's attitude is done by a recorded file describing his or her journey [36].

Therefore, it is necessary to ensure the presence of several scenarios related to the achievement of learning objectives, to provide feedback during and after the game [37]. Moreover, it is important to compare the students' actions and achievements with their satisfaction and motivation [13].

\subsection{Serious game and behavioral engagement}

Several authors have shown that integrating serious game into learning helps to raise the level of student engagement compared to traditional teaching methods.[5], [13], [16], [38].

Moreover, for Viau (1994), engagement is the indicator of school motivation, and it is most likely to have a direct impact on students' success [39], It involves "the initiation of action" and "active participation [40] et «la participation active» [41]. Furthermore, the work done on the subject defines three dimensions related to school engagement: behavioral, cognitive, and affective aspects [42]-[44].

According to Blumenfeld and al (2005), behavioral engagement can be seen as a continuum of participation, essentially referring to the positive or negative behaviors that the learner demonstrates in school and class [45], [46]. Positive behaviors include following instructions, involvement in school tasks and activities proposed by the teacher, and participation in extracurricular activities [44], [47]. Negative behaviors include absenteeism, disruptive behavior, and lack of academic effort [48], [49].

Today, the use of technology in the teaching and learning process promotes student engagement and motivation. Indeed, a series of studies conducted by Corno and Mandinach demonstrate links between the use of digital technologies, motivation, engagement, and performance of students [50].

Moreover, the implementation of online learning activities generates a large number of traces that allow us to analyze what learners do in real-time about what was 
expected [51], [52]. In our study, these indices allow us to analyze the behavioral engagement of students in their learning process.

Indeed, the serious game allows keeping the learners' activities in the form of logs, which generates traces of the different pages visited and the different actions performed. This traceability is a good indicator to better understand the learners' behavior and therefore to have a clear idea of their behavioral engagement. These traces can also be transformed to represent a measure of behavioral engagement [53].

\subsection{Serious game and motivation}

The serious game is an effective tool for stimulating student motivation because it uses technology [5], [16]. Therefore, measuring the levels of motivation in the student allows us to diagnose the problems encountered throughout the learning process and the factors that influence them. Moreover, the use of Keller's ARCS model (2010) on the motivational design of a technology-based instructional program (IMMS) allows for the measurement of motivation through the collection of information necessary to determine the strengths and weaknesses of the serious game used to support learning [25]. It is based on four factors of motivation namely: attention, relevance, confidence and satisfaction [25], [54], [55].

The first factor is attention, it consists of stimulating the learners' curiosity. The second factor is relevance, it is based on the adequacy between the objectives and the needs expressed by the learners. The third factor, confidence, is based on the guarantee of feelings of control and hope of success, which pushes the student to make more effort in the activities to achieve the objectives. Finally, the last factor is based on the evaluation and interpretation of the results obtained by the students, to determine their level of satisfaction, and to maintain their motivation [56], [57].

\section{Methodology}

\subsection{Participants}

The experimental study's participants $(n=58)$ were second-year polyvalent nursing students in the Bachelor's degree program in nursing at Casablanca's High Institute of Nursing and Health Techniques.

\subsection{Data collection methods}

The methodological approach addresses three components. The first aims to measure the effects of the serious game on the clinical learning of nursing students through their theoretical and practical summative scores. It is a randomized quasiexperimental study with two groups one experimental and one control group. The polyvalent nursing students $(\mathrm{n}=58)$ were randomly divided into two groups; experimental group $1(n=29)$ and control group $2(n=29)$. Both groups received the same content taught at a distance during the lock-in period on "pediatric nursing". Only the 
experimental group received an online serious game that was played in three scenarios with an embedded assessment system in each scenario played. The purpose of the assessment embedded in the game was to study the degree of mastery of pediatric nursing knowledge and skills.

The module taught was designed to help students acquire knowledge and skills in pediatric nursing before their integration into the clinical placement. Based on this, both groups received the same traditional assessments. Thus, two assessments were scheduled after the end of the lock-in; a written MCQ exam and a practical exam to measure the effects of the serious game on the clinical learning of the nursing students.

The second part of the study is based on the analysis of the students' activity traces provided by the VTS Editor platform and on the distribution of a questionnaire to 29 students. The latter is developed from Killer's model (2010), and it focuses on measuring the levels of motivation among the students of the experimental group to study their satisfaction with the serious game and its impact on their motivation. The 36item questionnaire has four factors related to attention, relevance, confidence, and satisfaction.

The third part of the study focuses on the evaluation of the learners' engagement in the game scenarios through the indicators provided on VTS Perform, namely participation, punctuality in the completion of the game, number of attempts, and follow-up of the completion of the tests and the game.

\subsection{Experimental study design}

The design of the serious game is based on Kiili's (2005) model for the construction of an appropriate learning environment and a review of the literature on the design of educational scenarios in serious games.

It consists of three scenarios on three pediatric nursing practices (gastric feeding, peripheral venous access, bronchial aspiration) designed according to the care process: diagnosis, material, technique, evaluation, and monitoring. Moreover, the scenarios were designed in close consultation with the teacher of the module, and two teachers trained in virtual simulation and gamification.

For each element of the process, the objectives to be achieved and the history of the framework are specified, as well as the presence of a scoring system based on scores, challenges, and feedback to help the student make decisions based on the reactions of the virtual patient.

The serious game is designed in the VTS Editor Education version 2 platform and is accessible via the VTS Player platform. While the follow-up of the progress of each student is ensured on VTS Perform, it allows to know the course of each student in the game, the number of his/her attempts, his/her mistakes, the scores obtained in each stage, and a final detailed assessment for each student. 


\subsection{Analysis of the results}

The data from the experimental study are analyzed by SPSS version 22 software. Student's t-test for two independent samples is used to compare the summative scores of the two experimental and control groups, while the questionnaire data were submitted to descriptive statistical analysis.

\subsection{Process followed}

Several actions are undertaken to facilitate the student's access to the game in a distance learning period; (1) the creation of a personal account for each student with a username and password. (2) Sending activation invitations for each student. (3) Explanation of how to use VTS Player with a virtual remote demonstration. (4) Daily remote support for each student to become familiar with the learning tool, to solve access difficulties, to answer questions. (5) Monitoring the progress of each student, with reminders to play a scenario or complete it.

\subsection{Ethical considerations}

Permission to conduct the study is obtained from the Ministry of Health and the management of ISPITS in Casablanca. In addition, the ethical principles of free and informed consent, anonymity, and confidentiality are taken into account.

\section{Results}

\subsection{Results of the experimental study}

According to the data analysis, the average summative score for the written test for the experimental group is 15.09 points, whereas it is 14.14 points for the control group. Furthermore, the average summative score for the practical test in the experimental group is 14.95 points, whereas it is 14.78 points in the control group.

The results of Student's t-test for two independent samples show the presence of an average difference of -0.95 for the written exam and -0.16 for the practical exam between the two groups of students. However, this difference is statistically significant for the former $(\mathrm{t}=-2.706, \mathrm{p}=0.009)$ while it is not significant for the latter $(\mathrm{t}=$ 0.373, $\mathrm{p}=0.711)$. (See Table 1).

Table 1. Difference between students' Means in the written and practical examination

\begin{tabular}{|c|c|c|c|c|c|c|}
\hline \multicolumn{2}{|c|}{ Categories } & n & Mean and standard deviation & t & df & p-value \\
\hline \multirow{2}{*}{ Theoretical examination } & Control & 29 & $14,14(1.54)$ & \multirow{2}{*}{-2.706} & 50.53 & \multirow{2}{*}{0.009} \\
\cline { 2 - 8 } & Experimental & 29 & $15,09(1.08)$ & & \\
\hline \multirow{2}{*}{ practical examination } & Control & 29 & $14,78(1.55)$ & -0.373 & 56 & \multirow{2}{*}{0.711} \\
\cline { 2 - 8 } & experimental & 29 & $14,95(1.77)$ & & \\
\hline
\end{tabular}




\subsection{The behavioral engagement of students through the analysis of follow-up} traces

The evaluation of the learners' engagement in the implementation of the game scenarios is based on the indicators provided on VTS Perform. These are the actions that the students have performed and that allow to consider the student as active. In our case, these indicators are; participation and punctuality in the realization of the game, the number of attempts (effort). (See Table 2).

Table 2. Analysis of Learner Access

\begin{tabular}{|l|c|c|c|c|c|c|c|c|}
\hline \multicolumn{1}{|c|}{ Days } & Sunday & Monday & Tuesday & Wednesday & Thursday & Friday & Saturday & Sunday \\
\hline Morning (6H to $12 \mathrm{H})$ & 0 & 0 & 0 & 0 & 0 & 0 & 0 & 0 \\
\hline Afternoon (12H to $18 \mathrm{H})$ & 24 & 02 & 01 & 28 & 03 & 02 & 05 & 04 \\
\hline Evening (18H to 24H) & 0 & 0 & 19 & 0 & 02 & 13 & 0 & 01 \\
\hline After midnight (24H to 6H) & 0 & 01 & 02 & 01 & 07 & 0 & 02 & 0 \\
\hline Overall time spent (in min) & 189,57 & 60,11 & 200,8 & 404,61 & 161,04 & 163,56 & 137,84 & 51,74 \\
\hline Overall score achieved & 1264 & 1393 & 3203 & 4797 & 1506 & 1743 & 643 & 647 \\
\hline Number of attempts & 24 & 03 & 23 & 40 & 14 & 13 & 08 & 07 \\
\hline Completed scenario (number) & 06 & 01 & 12 & 19 & 08 & 03 & 03 & 03 \\
\hline
\end{tabular}

Table 2 explains the characteristics of students' access to the serious game throughout their participation. In this case, the unit is the week. We can see that the majority of students participated in the game with 146 attempts. Also, access was based on availability; mostly in the afternoon and evening. In addition, we record the maximum access on Wednesday with the highest score (4797 points).

We notice that the students are committed to the completion of the game and the realization of the different integrated tests. Tracking the progress of each student shows that completion differs according to the time and availability of the students. (See Figure 1,2).

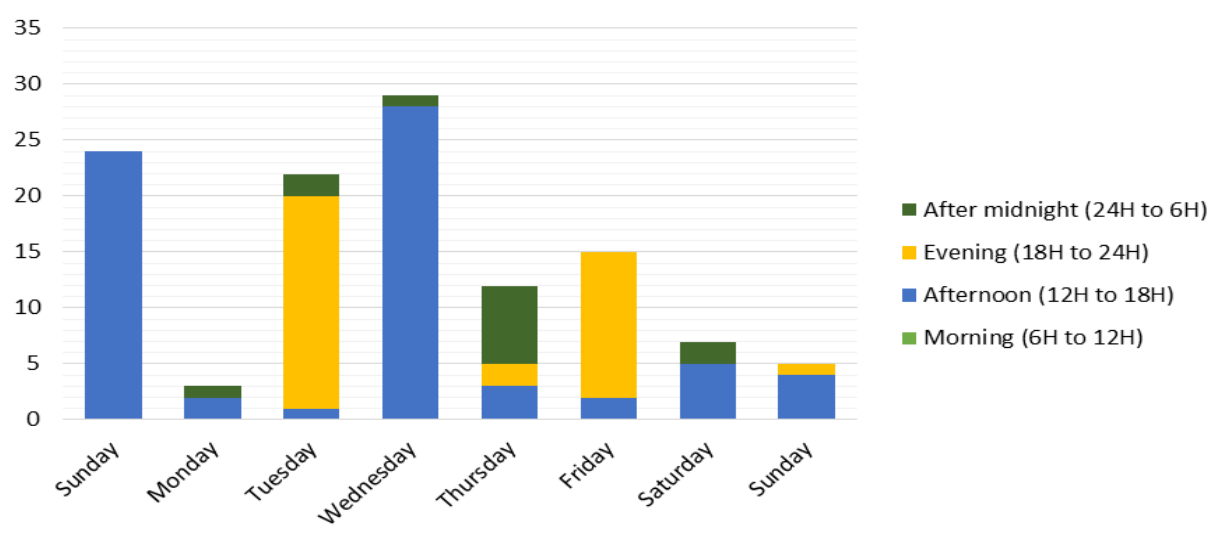

Fig. 1. Analysis of student access 


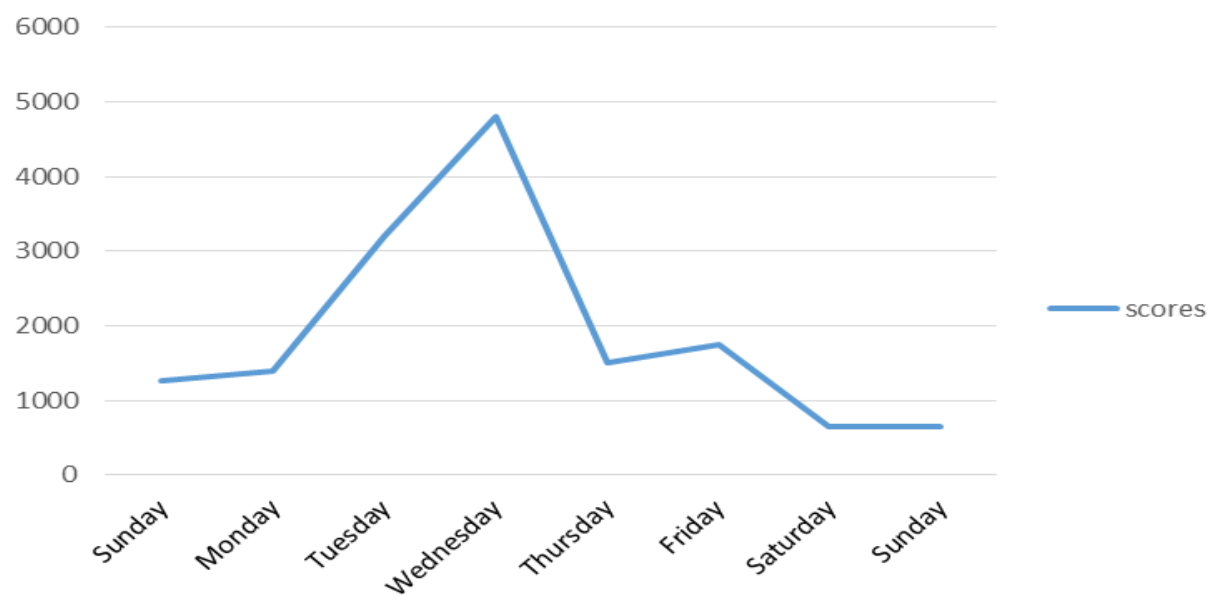

Fig. 2. The scores achieved by the students

\subsection{The result of the questionnaire survey}

The test of reliability of the questionnaire by Cronbach's Alpha $(\alpha=0.80)$ shows that it is a valid and reliable measurement scale from a statistical point of view.

Socio-demographic characteristics of the participants. Data from 29 participants show a very young population of students between 19 and 24 years of age $(100 \%)$, with a predominance of women $(96.6 \%)$, of Moroccan nationality.

Students' motivation towards the serious game. With regard to the "attention" factor in the serious game, students express a positive perception when dealing with initial attention, content, and organization as well. The best-scored items are related to these aspects. There was something interesting at the beginning of the game that got my attention ( $4.79 \pm 0.41)$, the way the information is arranged in the game helped keep my attention ( $4.72 \pm 0.84)$, the variety of reading passages, activities, illustrations, etc., helped keep my attention on the game $(4.66 \pm 0.81)$. While the aspects related to unattractiveness and boredom in the game are the least scored; the design of the game looks dry and unappealing $(2.21 \pm 1.26)$ the style of writing in the game is boring (1.79 \pm 1.01$)$. (See Table 3).

Concerning the factor of "relevance", students assign more scores to features related to what is taught, usefulness of the game, response to their interest, importance of success $(4.83 \pm 0.46 ; 4.83 \pm 0.38 ; 4.69 \pm 0.47)$ (See Table 4$)$. 
Paper-The Impact of Serious Game on the Nursing Students' Learning, Behavioral Engagement and ...

Table 3. Students' scores on the attention factor in the serious game

\begin{tabular}{|l|l|c|c|}
\hline item & \multicolumn{1}{|c|}{ Description } & Mean & $\begin{array}{c}\text { Standard } \\
\text { deviation }\end{array}$ \\
\hline 2 & $\begin{array}{l}\text { There was something interesting at the beginning of the game that got my atten- } \\
\text { tion. }\end{array}$ & 4.79 & 0.41 \\
\hline 8 & The interface design of the game is eye-catching & 4.34 & 1.07 \\
\hline 11 & The quality of the writing in the game helped to hold my attention. & 4.62 & 0.67 \\
\hline 12 & The content of the game is so abstract that it was hard to keep my attention on it. & 2.41 & 1.32 \\
\hline 15 & The design of the game looks dry and unappealing. & 2.21 & 1.26 \\
\hline 17 & The way the information is arranged in the game helped keep my attention. & 4.72 & 0.84 \\
\hline 20 & The game has things that stimulated my curiosity. & 4.52 & 0.73 \\
\hline 22 & The amount of repetition in the game caused me to get bored sometimes. & 2.86 & 1.38 \\
\hline 24 & I learned some things that were surprising or unexpected with the game. & 4.00 & 1.13 \\
\hline 28 & $\begin{array}{l}\text { The variety of reading passages, activities, illustrations, etc., helped keep my } \\
\text { attention on the game. }\end{array}$ & 4,66 &, 81 \\
\hline 29 & The style of writing in the game is boring. & 1,79 & 1,01 \\
\hline 31 & There are so many words on each game screen/page that it is irritating. & 2,24 & 1,43 \\
\hline
\end{tabular}

Table 4. Students' scores on the relevance factor in the serious game

\begin{tabular}{|l|l|c|c|}
\hline item & \multicolumn{1}{|c|}{ Description } & Mean & $\begin{array}{c}\text { Standard } \\
\text { deviation }\end{array}$ \\
\hline 6 & It is clear to me how the content of the game is related to things I already know. & 4,83 &, 46 \\
\hline 9 & $\begin{array}{l}\text { There were examples that showed me how the game could be important to some } \\
\text { people in the learning setting. }\end{array}$ & 4,62 &, 67 \\
\hline 10 & Completing activities in the game successfully was important to me. & 4,69 &, 54 \\
\hline 16 & The content of the game is relevant to my interests. & 4,69 &, 47 \\
\hline 18 & $\begin{array}{l}\text { There are explanations or examples of how people use the knowledge in the } \\
\text { game. }\end{array}$ & 4,69 &, 60 \\
\hline 23 & $\begin{array}{l}\text { The content and style of writing in the game convey the impression that its } \\
\text { content is worth knowing. }\end{array}$ & 3,83 & 1,13 \\
\hline 26 & The game was not relevant to my needs because I already knew most of it. & 1,93 &, 92 \\
\hline 30 & $\begin{array}{l}\text { I could relate the content of the game to things I have seen, done or thought } \\
\text { about in my own life. }\end{array}$ & 4,48 &, 68 \\
\hline 33 & The content in the game will be useful to me. & 4,83 &, 38 \\
\hline
\end{tabular}

For the "confidence" factor, students appreciate the orienting information in the introduction $(4.83 \pm 0.53)$, the feelings of confidence $(4.69 \pm 0.80)$ and the ability to learn the content $(4.66 \pm 0.53)$ that the serious game provides. However, the difficulty aspects were the lowest-rated; The activities in the game were too difficult $(2.03 \pm 1.23)$ The game was more difficult to understand than I would like for it to be $(1.83 \pm 1.13)$ (See Table 5). 
Paper-The Impact of Serious Game on the Nursing Students' Learning, Behavioral Engagement and ...

Table 5. Students' scores on the confidence factor in the serious game

\begin{tabular}{|l|l|c|c|}
\hline item & \multicolumn{1}{|c|}{ Description } & Mean $\begin{array}{c}\text { Standard } \\
\text { deviation }\end{array}$ \\
\hline 1 & When I first looked at the game, I had the impression that it would be easy for me. & 4,52 &, 57 \\
\hline 3 & The game was more difficult to understand than I would like for it to be. & 1,83 & 1,13 \\
\hline 4 & $\begin{array}{l}\text { After reading the introductory information, I felt confident that I knew what I was } \\
\text { supposed to learn from the game. }\end{array}$ & 4,83 &, 53 \\
\hline 7 & $\begin{array}{l}\text { The game had so much information that it was hard to pick out and remember the } \\
\text { important points. }\end{array}$ & 2,52 & 1,55 \\
\hline 13 & As I worked on the game, I was confident that I could learn the content. & 4,66 &, 55 \\
\hline 19 & The activities in the game were too difficult. & 2,03 & 1,23 \\
\hline 25 & $\begin{array}{l}\text { After working on the game for a while, I was confident that I would be able to pass } \\
\text { a test on the content. }\end{array}$ & 4,41 &, 62 \\
\hline 34 & I could not really understand quite a bit of the material in the game. & 2,03 & 1,08 \\
\hline 35 & $\begin{array}{l}\text { The good organization of the content in the game helped me be confident that I } \\
\text { would learn this material. }\end{array}$ & 4,69 &, 80 \\
\hline
\end{tabular}

Regarding the "satisfaction" factor in the serious game, the students express a very positive appreciation of the serious game and the feedback integrated into all activities. Besides, the following items are the most important for them; I really enjoyed learning with the game $(4.83 \pm 0.38)$ the wording of feedback after the exercises, or of other comments in the game, helped me feel rewarded for my effort $(4.79 \pm 0.49)$ it was a pleasure to work on such a well-designed game (4.72 \pm 0.64$)$. (See Table 6).

Table 6. Students' scores on the satisfaction factor in the serious game

\begin{tabular}{|l|l|c|c|}
\hline item & \multicolumn{1}{|c|}{ Description } & Mean & $\begin{array}{c}\text { Standard } \\
\text { deviation }\end{array}$ \\
\hline 5 & Completing the exercises in the game gave me a satisfying feeling of accomplishment. & 4,69 &, 541 \\
\hline 14 & I enjoyed the game so much that I would like to know more about this topic. & 4,72 &, 455 \\
\hline 21 & I really enjoyed learning with the game. & 4,83 &, 384 \\
\hline 27 & $\begin{array}{l}\text { The wording of feedback after the exercises, or of other comments in the game, } \\
\text { helped me feel rewarded for my effort. }\end{array}$ & 4,79 &, 491 \\
\hline 32 & If felt good to successfully complete the game. & 4,52 &, 871 \\
\hline 36 & It was a pleasure to work on such a well-designed game. & 4,72 &, 649 \\
\hline
\end{tabular}

When comparing the mean and standard deviations of the motivation factors, we find that the satisfaction factor had the highest score $(4.71 \pm 0.34)$ followed by the relevance, attention, and confidence factors. (See Table 7).

Table 7. Ranking of motivation factors by the degree of importance according to students

\begin{tabular}{|c|c|c|c|}
\hline \multirow{4}{*}{ Group } & Dimensions/level of importance & Mean & Standard deviation \\
\hline \multirow{4}{*}{ Students } & satisfaction & 4.71 & 0.34 \\
\cline { 2 - 4 } & relevance & 4.28 & 0.32 \\
\cline { 2 - 4 } & Attention & 3.59 & 0.44 \\
\cline { 2 - 4 } & confidence & 3.50 & 0.40 \\
\hline
\end{tabular}




\section{Discussion}

This study was conducted at ISPITS in Casablanca to investigate the impact of the serious game on pediatric nursing students' learning, behavioral engagement, and motivation. The findings indicate a positive impact on nursing care acquisition and motivation among polyvalent nursing students.

Indeed, the experimental study demonstrated a positive effect of the serious game on the learning of pediatric nursing care in second-year polyvalent nursing students. The summative scores of the two groups were compared using Student's t-test for two independent samples. According to the results, the serious game allows for an improvement in students' clinical knowledge acquisition in pediatric nursing. However, this study showed that it did not have an effect on clinical nursing skills.

these results corroborate with the results of Tan and al (2017) study, which showed that the average post-test scores of knowledge and self-confidence among the participants in the experimental group improved significantly $(p<0.001)$ after the intervention of the blood transfusion serious game. However, no significant difference $p$ $=0.11$ was found between the two groups on the average post-test performance scores [31].

Similarly, Checa and Bustillo (2020) showed little improvement in students' skills although high levels of motivation, engagement, and interest were found [5].

Furthermore, the results of the questionnaire survey showed that the serious game has a positive impact on students' motivation throughout the learning process. The students expressed their satisfaction with the serious game, due to its relevance, its ability to attract their attention and create feelings of confidence. In the same sense, Fonseca and al (2015) state that students highly appreciated the serious game for its easy use at any time and place respecting their learning pace, its didactic design. It gives students access to feedback based on their actions and mistakes, and it motivates them to be active and independent in their learning in order to develop their abilities and gain new knowledge [6], [58].

In addition, according to De Serio and al (2013), the high scores attributed to the factors of attention (3.76) and confidence (3.63) followed by satisfaction and relevance demonstrate the positive impact of virtual learning on the motivation of students, leading them to achieve high levels of engagement in learning activities with less cognitive effort [25], [55].

Indeed, the analysis of the traces through the indicators provided by VTS Perform, allow us to appreciate the commitment of the learners in the serious game through their daily participation, the punctuality in the realization of the game, the number of attempts which is 146 and the follow-up of the completion of the tests by the scores. In the same vein, Thomas, Wadsworth, Jin, and Thunders (2016) demonstrate along with self-assessment test scores, the number of attempts also has a significant impact on learning quality. This leads us to find that the use of serious game positively impacts student engagement and persistence [59].

Besides, the use of serious games in nursing education is based on the increase of learning efficiency, strong motivation, and the involvement and commitment of the learner in the clinical environment by achieving educational training objectives in 
virtual situations [16], [30]. It is a complementary learning tool to optimize the acquisition of clinical skills during simulation [16], [31].

Thus, it is possible to adopt a mixed approach combining the serious game for the learning of clinical knowledge followed by the simulation for the acquisition of skills and clinical competencies. This approach acts on the student's confidence in his abilities and the reduction of his anxiety during clinical learning.

\section{Conclusion}

This study was carried out at the ISPITS in Casablanca to study the impact of the serious game on the learning of nursing care in pediatrics among nursing students and on their motivation. The major results show, on the one hand, the positive impact of the game on the learning of clinical knowledge in nursing through the comparison of the scores obtained by the two experimental and control groups and on the other hand, its impact on the motivation of the polyvalent nursing students, who strongly express their satisfaction with the game and also their engagement in learning.

However, it is necessary to repeat the experience of the serious game in several nursing modules to obtain reliable results. Further studies must be conducted on the impact of combining serious gaming with simulation on the acquisition and improvement of clinical skills and competencies of nursing students.

\section{$7 \quad$ Limitations of the study}

The present study was conducted to investigate the impact of the serious game on nursing students' learning and motivation and has some limitations: namely, its small sample size, and its focus on a single module with a single profile of polyvalent nursing students. As a consequence, the possibility of generalizing the results obtained is limited.

Furthermore, the impact study was conducted in the short term, but in order to draw significant conclusions, the impact must be studied in the long term as well.

\section{References}

[1] J. M. R. Arafeh, "Simulation-Based Training: The Future of Competency?," Journal of Perinatal \& Neonatal Nursing, vol. 25, no. 2, pp. 171-174, Apr. 2011. https://doi.org/ $\underline{\text { 10.1097/JPN.0b013e3182116e55 }}$

[2] M. de S. Silveira and A. L. P. Cogo, "Contribuições das tecnologias educacionais digitais no ensino de habilidades de enfermagem: revisão integrativa," Rev. Gaúcha Enferm., vol. 38, no. 2, 2017. https://doi.org/10.1590/1983-1447.2017.02.66204

[3] A.-M. Gallo, "Beyond the Classroom: Using Technology to Meet the Educational Needs of Multigenerational Perinatal Nurses," Journal of Perinatal \& Neonatal Nursing, vol. 25, no. 2, pp. 195-199, Apr. 2011. https://doi.org/10.1097/JPN.0b013e3182163993

[4] L. M. M. Fonseca et al., "Development of the e-Baby Serious Game With Regard to the Evaluation of Oxygenation in Preterm Babies: Contributions of the Emotional Design," 
Paper-The Impact of Serious Game on the Nursing Students' Learning, Behavioral Engagement and ...

CIN: Computers, Informatics, Nursing, vol. 32, no. 9, pp. 428-436, Sep. 2014. https://doi. org/10.1097/CIN.0000000000000078

[5] D. Checa and A. Bustillo, "A review of immersive virtual reality serious games to enhance learning and training," Multimed Tools Appl, vol. 79, no. 9-10, pp. 5501-5527, Mar. 2020. https://doi.org/10.1007/s11042-019-08348-9

[6] L. M. M. Fonseca, N. D. A. Aredes, D. M. V. Dias, C. G. S. Scochi, J. C. A. Martins, and M. A. Rodrigues, "Serious game e-Baby: nursing students' perception on learning about preterm newborn clinical assessment," Rev Bras Enferm., p. 7, 2015.

[7] P. Moule, K. Pollard, J. Armoogum, and S. Messer, "Virtual patients: Development in cancer nursing education," Nurse Education Today, vol. 35, no. 7, pp. 875-880, Jul. 2015. https://doi.org/10.1016/j.nedt.2015.02.009

[8] J. M. Anderson, K. B. Boyle, A. A. Murphy, K. A. Yaeger, J. LeFlore, and L. P. Halamek, "Simulating Extracorporeal Membrane Oxygenation Emergencies to Improve Human Performance. Part I: Methodologic and Technologic Innovations," Simulation in Healthcare: The Journal of the Society for Simulation in Healthcare, vol. 1, no. 4, pp. 220-227, 2006. https://doi.org/10.1097/01.SIH.0000243550.24391.ce

[9] C. Y. N. Hara, N. D. A. Aredes, L. M. M. Fonseca, R. C. de C. P. Silveira, R. A. A. Camargo, and F. S. N. de Goes, "Clinical case in digital technology for nursing students" learning: An integrative review," Nurse Education Today, vol. 38, pp. 119-125, Mar. 2016. https://doi.org/10.1016/j.nedt.2015.12.002

[10] J. M. Taekman and K. Shelley, "Virtual Environments in Healthcare: Immersion, Disruption, and Flow," International Anesthesiology Clinics, vol. 48, no. 3, pp. 101-121, 2010. https://doi.org/10.1097/AIA.0b013e3181eace73

[11] N. Zary, G. Johnson, J. Boberg, and U. G. Fors, "Development, implementation and pilot evaluation of a Web-based Virtual Patient Case Simulation environment - Web-SP," BMC Med Educ, vol. 6, no. 1, p. 10, Dec. 2006. https://doi.org/10.1186/1472-6920-6-10

[12] M. Graafland, J. M. Schraagen, and M. P. Schijven, "Systematic review of serious games for medical education and surgical skills training," British Journal of Surgery, vol. 99, no. 10, pp. 1322-1330, Sep. 2012. https://doi.org/10.1002/bjs.8819

[13] É. Sanchez, M. Ney, and J.-M. Labat, "Jeux sérieux et pédagogie universitaire : de la conception à l'évaluation des apprentissages," Revue internationale des technologies en pédagogie universitaire, vol. 8, no. 1-2, p. 48, 2011. https://doi.org/10.7202/1005783ar

[14] N. Perreault, "Rôle et impact des TIC sur l'enseignement et l'apprentissage au collégial I," Pédagogie collégiale, vol. 16, no. 3, p. 8, 2003.

[15] J. Chin, R. Dukes, and W. Gamson, "Assessment in Simulation and Gaming: A Review of the Last 40 Years," Simulation \& Gaming, vol. 40, no. 4, pp. 553-568, Aug. 2009. https://doi.org/10.1177/1046878109332955

[16] F. Bellotti, B. Kapralos, K. Lee, P. Moreno-Ger, and R. Berta, "Assessment in and of Serious Games: An Overview," Advances in Human-Computer Interaction, vol. 2013, pp. 111, 2013. https://doi.org/10.1155/2013/136864

[17] R. Mehay, The Essential Handbook for GP Training and Education, Kindle edition. 2012. Accessed: Aug. 05, 2019. [Online]. Available: https://www.crcpress.com/The-EssentialHandbook-for-GP-Training-and-Education/Mehay/p/book/9781846195938

[18] G. Miller, "The Miller pyramid and prism," 1990. http://www.gp-training.net/training/ educational theory/adult learning/miller.htm (accessed Aug. 02, 2019).

[19] G. Mårtensson and A. Löfmark, "Implementation and student evaluation of clinical final examination in nursing education," Nurse Education Today, vol. 33, no. 12, pp. 15631568, Dec. 2013. https://doi.org/10.1016/j.nedt.2013.01.003 
Paper-The Impact of Serious Game on the Nursing Students' Learning, Behavioral Engagement and ...

[20] M. Phaneuf, “L'apprentissage/Enseignement En Milieu Clinique - PDF," 2006. https://docplayer.fr/15541878-L-apprentissage-enseignement-en-milieu-clinique.html (accessed Aug. 08, 2019).

[21] J. Bloomfield, C. Fordham-Clarke, A. Pegram, and B. Cunningham, "The development and evaluation of a computer-based resource to assist pre-registration nursing students with their preparation for objective structured clinical examinations (OSCEs)," Nurse Education Today, vol. 30, no. 2, pp. 113-117, Feb. 2010. https://doi.org/10.1016/j.nedt.2009 .06 .004

[22] K. Kiili, "Content creation challenges and flow experience in educational games: The ITEmperor case," The Internet and Higher Education, vol. 8, no. 3, pp. 183-198, Jul. 2005. https://doi.org/10.1016/j.iheduc.2005.06.001

[23] K. Kiili, "Evaluations of an Experiential Gaming Model," Human Technology, vol. 2, no. 2, pp. 187-201, Oct. 2006.

[24] F. Djelil, "Conception et évaluation d'un micromonde de Programmation Orientée-Objet fondé sur un jeu de construction et d'animation 3D," Université Blaise Pascal - Clermont II, Clermont-Ferrand, 2016.

[25] Á. Di Serio, M. B. Ibáñez, and C. D. Kloos, "Impact of an augmented reality system on students' motivation for a visual art course," Computers \& Education, vol. 68, pp. 586596, Oct. 2013. https://doi.org/10.1016/j.compedu.2012.03.002

[26] M. Hutton et al., "Numeracy for nursing, report of a pilot study to compare outcomes of two practical simulation tools - An online medication dosage assessment and practical assessment in the style of objective structured clinical examination," Nurse Education Today, vol. 30, no. 7, pp. 608-614, Oct. 2010. https://doi.org/10.1016/j.nedt.2009.12.009

[27] W. E. M. El Idrissi, G. Chemsi, K. E. Kababi, and M. Radid, "Assessment Practices of Student's Clinical Competences in Nurse Education,” TONURSJ, vol. 15, no. 1, pp. 47-54, Mar. 2021. https://doi.org/10.2174/1874434602115010047

[28] W. D. Huang, T. E. Johnson, and S.-H. C. Han, "Impact of online instructional game features on college students' perceived motivational support and cognitive investment: A structural equation modeling study," The Internet and Higher Education, vol. 17, pp. 5868, Apr. 2013. https://doi.org/10.1016/j.iheduc.2012.11.004

[29] J. Lothian and J. Ryoo, "Critical Factors and Resources in Developing a Game-Based Learning (GBL) Environment Using Free and Open Source Software (FOSS)," Int. J. Emerg. Technol. Learn., vol. 8, no. 6, p. 11, Nov. 2013. https://doi.org/10.3991/ ijet.v8i6.2918

[30] C. Arthur, T. Levett-Jones, and A. Kable, "Quality indicators for the design and implementation of simulation experiences: A Delphi study," Nurse Education Today, vol. 33, no. 11, pp. 1357-1361, Nov. 2013. https://doi.org/10.1016/j.nedt.2012.07.012

[31] A. J. Q. Tan et al., "Designing and evaluating the effectiveness of a serious game for safe administration of blood transfusion: A randomized controlled trial," Nurse Education Today, vol. 55, pp. 38-44, Aug. 2017. https://doi.org/10.1016/j.nedt.2017.04.027

[32] C. Wang and L. Huang, "A Systematic Review of Serious Games for Collaborative Learning: Theoretical Framework, Game Mechanic and Efficiency Assessment," Int. J. Emerg. Technol. Learn., vol. 16, no. 06, p. 88, Mar. 2021. https://doi.org/10.3991/ijet.v16i06. 18495

[33] S. Erhel and E. Jamet, "Digital game-based learning: Impact of instructions and feedback on motivation and learning effectiveness," Computers \& Education, vol. 67, pp. 156-167, Sep. 2013. https://doi.org/10.1016/j.compedu.2013.02.019 
Paper-The Impact of Serious Game on the Nursing Students' Learning, Behavioral Engagement and ...

[34] B. Goldberg and J. Cannon-Bowers, "Feedback source modality effects on training outcomes in a serious game: Pedagogical agents make a difference," Computers in Human Behavior, vol. 52, pp. 1-11, Nov. 2015. https://doi.org/10.1016/j.chb.2015.05.008

[35] D. Ifenthaler, D. Eseryel, and X. Ge, Eds., Assessment in Game-Based Learning: Foundations, Innovations, and Perspectives, 2012th edition. New York ; London: Springer, 2012.

[36] J. A. Caballero-Hernández, M. Palomo-Duarte, and J. M. Dodero, "Skill assessment in learning experiences based on serious games: A Systematic Mapping Study," Computers \& Education, vol. 113, pp. 42-60, Oct. 2017. https://doi.org/10.1016/j.compedu.2017 .05 .008

[37] J. Hattie and H. Timperley, "The Power of Feedback," Review of Educational Research, vol. 77, no. 1, pp. 81-112, Mar. 2007. https://doi.org/10.3102/003465430298487

[38] V. Shute, S. Rahimi, and B. Emihovich, "Assessment for Learning in Immersive Environments," in Virtual, Augmented, and Mixed Realities in Education, D. Liu, C. Dede, R. Huang, and J. Richards, Eds. Singapore: Springer Singapore, 2017, pp. 71-87. https://doi.org/10.1007/978-981-10-5490-7 5

[39] J. Houssaye, "Viau (Rolland). — La motivation en contexte scolaire," Revue française de pédagogie, vol. 113, no. 1, pp. 154-155, 1995.

[40] J. P. Connell, "Context, self, and action: A motivational analysis of self-system processes across the life span," in The self in transition: Infancy to childhood, Chicago, IL, US: University of Chicago Press, 1990, pp. 61-97.

[41] S. Parent, "De la motivation à l'engagement : un processus multidimensionnel lié à la réussite de vos étudiants," Pédagogie collégiale, vol. 27, pp. 13-16, Apr. 2014.

[42] E. Chapman, "Alternative Approaches to Assessing Student Engagement Rates," practical Assessment,research and Evaluation, vol. 8, no. 13, 2002. https://doi.org/10.7275/3E6E8353

[43] E. A. Skinner and M. J. Belmont, "Motivation in the Classroom: Reciprocal Effects of Teacher Behavior and Student Engagement Across the School Year," journal of educational psychology, vol. 85, no. 4, p. 11, 1993. https://doi.org/10.1037/0022-0663.85.4.571

[44] J. A. Fredricks, P. C. Blumenfeld, and A. H. Paris, "School Engagement: Potential of the Concept, State of the Evidence," Review of Educational Research, vol. 74, no. 1, pp. 59109,2004

[45] P. Blumenfeld et al., "School Engagement of Inner-City Students During Middle Childhood," in Developmental Pathways Through Middle Childhood, Psychology Press, 2005.

[46] M. Abdulaziz Alsubhi, N. Sahari, and T. S. M. Tengku Wook, "A Conceptual Engagement Framework for Gamified E-Learning Platform Activities," Int. J. Emerg. Technol. Learn., vol. 15, no. 22, p. 4, Nov. 2020. https://doi.org/10.3991/ijet.v15i22.15443

[47] M. J. Furlong and S. L. Christenson, "Engaging students at school and with learning: A relevant construct forall students," Psychol. Schs., vol. 45, no. 5, pp. 365-368, May 2008. https://doi.org/10.1002/pits.20302

[48] J. D. Finn and D. A. Rock, "Academic Success Among Students at Risk for School Failure," p. 14.

[49] R. Balfanz, L. Herzog, and D. J. Mac Iver, "Preventing Student Disengagement and Keeping Students on the Graduation Path in Urban Middle-Grades Schools: Early Identification and Effective Interventions," Educational Psychologist, vol. 42, no. 4, pp. 223-235, Nov. 2007. https://doi.org/10.1080/00461520701621079

[50] L. Corno and E. B. Mandinach, "The role of cognitive engagement in classroom learning and motivation," Educational Psychologist, vol. 18, no. 2, pp. 88-108, Jun. 1983. https:// doi.org/10.1080/00461528309529266 
Paper-The Impact of Serious Game on the Nursing Students' Learning, Behavioral Engagement and ...

[51] G. Chemsi, M. Sadiq, M. Radid, and M. Talbi, "Formative E-Assessment and Behavioral Commitment of Students: Case of the Faculty of Science Ben M'sik," Int. J. Emerg. Technol. Learn., vol. 14, no. 12, p. 4, Jun. 2019. https://doi.org/10.3991/ijet.v14i12.10389

[52] jean-luc Gilles and jean-guy Blais, Évaluation des apprentissages et technologies de l'information et de la communication. Le futur est à notre porte |, Presses de l'universite laval. 2011. Accessed: Aug. 13, 2021. [Online]. Available: https://www.pulaval.com/ produit/evaluation-des-apprentissages-et-technologies-de-l-information-et-de-la-communic ation-le-futur-est-a-notre-porte

[53] B. Poellhuber, N. Roy, and I. Bouchoucha, "Les relations entre attentes, valeur, buts, engagement cognitif et engagement comportemental dans un MOOC," RITPU, vol. 13, no. 2-3, p. 111, 2016. https://doi.org/10.18162/ritpu-2016-v13n23-08

[54] D. Wenhao Huang, H. Diefes-Dux, P. K. Imbrie, B. Daku, and J. G. Kallimani, "Learning motivation evaluation for a computer-based instructional tutorial using ARCS model of motivational design," in 34th Annual Frontiers in Education, 2004. FIE 2004., Savannah, GA, USA, 2004, pp. 65-71. https://doi.org/10.1109/FIE.2004.1408466

[55] D. U. Bolliger, S. Supanakorn, and C. Boggs, "Impact of podcasting on student motivation in the online learning environment," Computers \& Education, vol. 55, no. 2, pp. 714-722, Sep. 2010. https://doi.org/10.1016/j.compedu.2010.03.004

[56] J. M. Keller, Motivational Design for Learning and Performance. Boston, MA: Springer US, 2010. https://doi.org/10.1007/978-1-4419-1250-3

[57] L. Haas, "Reprints available directly from the publisher Photocopying permitted by license only," Review of Education, Pedagogy, and Cultural Studies, vol. 17, no. 1, pp. 1-6, Jan. 1995. https://doi.org/10.1080/1071441950170102

[58] D. Sutter Widmer and N. Szilas, "Motivation, comportement dans le jeu et expérience de jeu: une relation aux multiples facettes," stice, vol. 24, no. 1, pp. 265-297, 2017. https://doi.org/10.3406/stice.2017.1733

[59] J. A. Thomas, D. Wadsworth, Y. Jin, J. Clarke, R. Page, and M. Thunders, "Engagement with online self-tests as a predictor of student success," Higher Education Research \& Development, vol. 36, no. 5, pp. 1061-1071, Jul. 2017. https://doi.org/10.1080/07294360. $\underline{2016.1263827}$

\section{Authors}

WIssam El Machtani El Idrissi is a Ph. Dc in Educational Technology. She is Nurse Teacher at the Higher Institute of Nursing and Health Techniques of Casablanca. She is a member of Association for Development of Evaluation Methodologies in Education (ADMEE)-section Morocco. She is a member of Laboratory of Physical Chemistry of Materials at Ben M'Sick Faculty of sciences (LCPM), Hassan II University of Casablanca, Morocco.

Ghizlane Chemsi is a $\mathrm{PhD}$ in Educational technology. She is a professor at Ben M'Sick Faculty of sciences, Hassan II University of Casablanca, Morocco. BP 7955 Sidi Othmane. She operates in several fields of educational sciences: educational technologies and assessment, engineering of assessment. She is a member of the Obsevatory of Reasearch in Didactics and University Pedagogy (ORDIPU), member of Association for the Development of Evaluation Methodologies in Education (ADMEE)-section Morocco and the Multidisciplinary Laboratory in Sciences and Information Communication and Education Technology (LAPSTICE). 
Khadija El Kababi is a $\mathrm{PhD}$ in Physical Chemistry. She is a regional delegate of the Regional Centre for Education and Training Professions. Casablanca-Settat. Morocco. She is a member of Laboratory of Physical Chemistry of Materials at Ben M'Sick Faculty of sciences (LCPM), Hassan II University of Casablanca, Morocco. BP 7955 Sidi Othmane. She operates in several fields of educational sciences: educational technologies, engineering of assessment and chemistry didactics.

Mohamed Radid is a PhD in Physical Chemistry. He is currently the Vice Dean of the Ben M'Sick Faculty of sciences), Hassan II University of Casablanca, Morocco since 2014, BP 7955 Sidi Othmane. He is a member of the Observatory of Research in Didactics and University Pedagogy (ORDIPU), and member Board of Directors of Association for the development of Evaluation Methodologies in Education (ADMEE)-Europe. He is an expert in the fields of teaching and research on educational and technologies assessment, engineering of assessment, chemistry didactics, University Pedagogy.

Article submitted 2021-09-14. Resubmitted 2021-10-13. Final acceptance 2021-10-15. Final version published as submitted by the authors. 